\title{
Da Academia Real Militar ao Departamento de Geologia, do Instituto de Geociências, da Universidade Federal do Rio de Janeiro: a trajetória de uma coleção de minerais
} From the Military Royal Academy to the Geology Department in the Institute
of Geosciences of the Federal University of Rio de Janeiro: the trajectory of a
mineralogical collection

\author{
Cristina Moura Bastos', Marcio Ferreira Rangel ${ }^{\mathrm{II}}$ III, Cícera Neysi de Almeida' \\ Universidade Federal do Rio de Janeiro. Rio de Janeiro, Rio de Janeiro, Brasil \\ "IMuseu de Astronomia e Ciências Afins. Rio de Janeiro, Rio de Janeiro, Brasil \\ I'U Universidade Federal do Estado do Rio de Janeiro. Rio de Janeiro, Rio de Janeiro, Brasil
}

\begin{abstract}
Resumo: Este trabalho aborda a formação da coleção de minerais da antiga Escola Nacional de Engenharia (ENE) que, nos dias atuais, encontra-se parcialmente sediada no Museu da Geodiversidade, localizado no Instituto de Geociências, da Universidade Federal do Rio de Janeiro (IGEO/UFRJ). A formação desta coleção foi motivada pela transferência da coleção mineralógica Werner das dependências da Academia Real Militar (ARM) para o Museu Real (atual Museu Nacional), em 1818, ano de sua inauguração, ficando a ARM sem amostras minerais que servissem ao ensino prático das cadeiras de Geologia e de Mineralogia do curso de Engenharia. Em 1824, foram solicitadas ao Museu amostras em duplicata para a ARM, constituindo, assim, o núcleo inicial dessa coleção. Esse núcleo, ampliado através de compra e de doações, atingiu mais de 5.000 exemplares em 1883. Ao longo do tempo, a ARM recebeu diversas denominações, até que em 1937 foi batizada com o nome de Escola Nacional de Engenharia. Durante o período da ditadura militar, o IGEO/UFRJ recebeu parte do acervo mineralógico da ENE. O recadastramento, ora em curso, demonstrou que a instituição não abriga, hoje, mais de 1.000 exemplares, ignorando-se o destino do restante dessa coleção, que se destaca por sua relevância histórica e científica.
\end{abstract}

Palavras-chave: Museu. Museologia. Patrimônio. Mineralogia. Coleções mineralógicas. Ensino de Engenharia.

\begin{abstract}
This paper treats the formation of the mineral collection of the former National School of Engineering (ENE), which today is partially incorporated in the Museum of Geodiversity of the Institute of the Geosciences of the Federal University of Rio de Janeiro (IGEO/UFRJ). The collection was formed with material of the Werner Mineralogical Collection, transferred from the Royal Military Academy (ARM) for the inauguration of the Royal Museum (currently the National Museum) in 1818, leaving the ARM without minerals used in the practical teaching of Geology and Mineralogy classes of the Engineering course. In 1824, samples were requested in duplicate from the Museum for the Academy, constituting the initial nucleus of this mineralogical collection. This nucleus was expanded through purchase and donations, reaching more than 5.000 exemplars in 1883. As time went by, the Royal Military Academy has been given different names. In 1937, it was renamed as the National School of Engineering. During the military dictatorship, the IGEO/UFRJ received part of the mineralogical collection of the ENE. A new inventory, in the progress of elaboration, shows that the number of samples in the institution is less than 1,000 units. The location is not known of the rest of this collection, of great historical and scientific relevance.
\end{abstract}

Keywords: Museum. Museology. Heritage. Mineralogy. Mineralogical collections. Engineering teaching.

BASTOS, C. M., M. F. RANGEL \& C. N. ALMEIDA, 2017. Da Academia Real Militar ao Departamento de Geologia, do Instituto de Geociências, da Universidade Federal do Rio de Janeiro: a trajetória de uma coleção de minerais. Boletim do Museu Paraense Emílio Goeldi. Ciências Naturais 12(1): 109-127.

Autora para correspondência: Cristina Moura Bastos. Universidade Federal do Rio de Janeiro. Instituto de Geociências. Departamento de Geologia. Centro de Ciências da Matemática e da Natureza. Avenida Athos da Silveira Ramos, 274 - Cidade Universitária. Bloco G. Rio de Janeiro, RJ, Brasil. CEP 21941-116 (cristina.bastos@igeo.ufrj.br).

Recebido em 12/02/2016

Aprovado em 16/04/2017

Responsabilidade editorial: Fernando da Silva Carvalho Filho

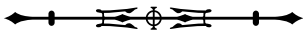




\section{INTRODUÇÃO}

acervo mineralógico do Museu da Geodiversidade (MGeo), pertencente ao Instituto de Geociências, da Universidade Federal do Rio de Janeiro (IGEO/UFRJ), alcança um número aproximado de quatro mil exemplares. Nesse momento, o acervo passa pelo processo de tratamento técnico, o que impede maior precisão de dados acerca do quantitativo já tratado e do quanto ainda falta para a conclusão desta etapa.

Nascido como Museu de Geologia, ligado inicialmente ao Departamento de Geologia do IGEO/NFRJ, teve seu nome modificado por iniciativa dos professores envolvidos no projeto de sua criação, os quais concluíram que este espaço serviria não apenas para divulgar a Geologia, mas também as Geociências de uma forma geral (Aracri, 2013). De acordo com o Regimento Interno do Museu da Geodiversidade, documento concluído em 2010, no capítulo I, intitulado "Da natureza jurídica do Museu”, está determinado no artigo $1^{\circ}$ :

O Museu da Geodiversidade (MGeo), instituído como órgão suplementar do Instituto de Geociências, o qual está inscrito no Cadastro Nacional de Pessoa Jurídica sob o n. 33663683/0032-12, constitui uma das Unidades pertencentes ao Centro de Ciências Matemáticas e da Natureza da Universidade Federal do Rio de Janeiro, reger-se-á segundo o disposto neste Regimento Interno e no seu Plano Museológico correspondente (UFRJ, 2010, p. 2).

No que se refere ao acervo de minerais e de rochas do MGeo, as ações de preservação, de documentação e a consequente disponibilização desse patrimônio cultural-científico-geológico são de vital importância para a produção da pesquisa, para a divulgação do conhecimento científico e para a ampliação das atividades educacionais.

Vale ressaltar que o recadastramento destas coleções (fechadas por décadas em salas da universidade) nos fez perceber uma lacuna de informações mais consistentes acerca da formação e da trajetória desse acervo, cuja origem remonta a duas conceituadas instituições de ensino: à Escola Nacional de Engenharia (ENE) e à Faculdade Nacional de Filosofia (FNFi), ambas sediadas no Rio de Janeiro.

Também integram este acervo as coleções formadas pelos professores do Departamento de Geologia da UFRJ, Jacques Pierre Cassedane e Othon Henry Leonardos; a coleção da Ward's', que no século XIX, e ainda hoje, abastece museus e instituições de ensino, com a comercialização de coleções de História Natural; além de outras coleções comerciais que serão citadas ao longo deste trabalho.

Em razão da impossibilidade de investigação da totalidade deste acervo em uma única etapa e como a coleção mineralógica da ENE se destaca por sua relevância histórica e científica, os autores optaram por torná-la objeto de sua pesquisa, ora divulgada neste artigo.

\section{MATERIAL E MÉTODOS}

A pesquisa foi baseada em fontes documental e bibliográfica, valendo-se de documentos existentes no Arquivo Nacional (AN), na Seção de Memória e Arquivo (SEMEAR), do Museu Nacional (MN/UFRJ), e no IGEO/UFRJ. A investigação foi ainda facilitada pelo fato de a primeira autora ser museóloga, servidora do MGeo, e ter contato direto e cotidiano com o acervo em questão.

O embasamento teórico foi feito por meio de pesquisa em documentos primários encontrados no AN, por antigos documentos de controle da coleção e por bibliografia que abordasse os seguintes tópicos: história da Engenharia, história institucional, formação e preservação de coleções de geociências, museus universitários, patrimônio natural, documentação museológica, museologia, memória e identidade. Documentos primários, como memorandos e ofícios

Ward's Natural Science Establishment, empresa comercial americana que, por volta de 1880, foi uma das responsáveis por abastecer os museus de História Natural com grande número de espécimes (Barrow, 2000 apud Grola, 2012, p. 210). 
depositados no AN, deram suporte a esta pesquisa, assim como alguns documentos em poder do IGEO/ UFRJ, como um antigo livro de registro das amostras, que pertenceu à ENE, e algumas etiquetas oriundas tanto da primitiva Escola Politécnica, como da já referida ENE. Os documentos primários encontrados foram revelados na íntegra, sendo atualizada a grafia da época.

Usando os diversos enfoques de Pomian (1984), Baudrillard (2002) e Possas (2005), trabalhou-se o conceito de coleção. Sob a perspectiva de Figueirôa (1997) e de Lopes (2009), abordou-se a institucionalização das ciências naturais no Brasil, já que ambas as autoras convergem no sentido de atribuir à criação dessas instituições a organização e a consolidação de uma cultura científica no país. A massa documental exigiu maior cautela e acuidade nas interpretações, mas pode revelar e responder a importantes questões que se impuseram à pesquisa: como foi constituído inicialmente o acervo mineralógico da ENE? Como se deu a ampliação desse acervo ao longo de sua trajetória? Quais perdas foram se sucedendo pela ausência de uma política adequada de conservação desse conjunto? Qual a relevância histórica e científica desse patrimônio? Valeu-se ainda de arquivos em mídia eletrônica e também de publicações em revistas especializadas, anais, periódicos, manuais, dissertações e teses.

\section{RESULTADOS E DISCUSSÃO}

\section{FORMAÇÃO E TRAJETÓRIA DA COLEÇÃO DE MINERAIS DA ENE}

Na perspectiva de Dohmann (2010), os valores simbólicos atribuídos pelos homens aos objetos os tornam fartos de sentidos e de significados. No começo, tudo eram coisas, enquanto, na atualidade, tudo inclina-se ao objeto. Os objetos vinculam-nos ao mundo, ativam nossas lembranças, remetem a memória às recordações de pessoas, fatos ou lugares e, na condição de artefatos produzidos pelo homem, comunicam experiências culturais. Ainda no entendimento de Dohmann (2010, p. 72): fluxo de sentidos e imagens que os objetos veiculam através dos canais de comunicação é capaz de despertar aspectos singulares das reminiscências dos indivíduos, recordações de vivências passadas que alternam tensões entre esquecimentos e lembranças, a partir do contato da materialidade do objeto com os sentidos e sensações possíveis que ele encerra. [...] O objeto é, portanto, prova documental que imprime suas marcas nos indivíduos, criando interna e externamente um processo dinâmico, comunicativo e intercultural.

Pomian (1984, p. 51) assim definiu o que considerava como objeto de coleção:

[...] qualquer conjunto de objetos naturais ou artificiais, mantidos temporária ou definitivamente fora do circuito das atividades econômicas, sujeitos a uma proteção especial num local fechado preparado para esse fim, e expostos ao olhar do público.

Este autor afirma ainda que todos os objetos são manipulados, exercem ou sofrem modificações físicas e consomem-se. Para ele, de um lado estão os semióforos, objetos que se expõem à contemplação, que não apresentam utilidade prática, mas sim um significado, e que, desse modo, representam o invisível. Do outro, estão os objetos inseridos em uma composição, que se oferecem ao uso e que, portanto, representam o visível. Pomian (1984) conclui que essas duas orientações, embora possam coexistir em certos casos excepcionais, são, todavia, opostas na maioria das vezes. Nas palavras de Pomian (1984, p. 72):

Existem pelo menos três situações possíveis: uma coisa tem apenas utilidade sem ter significado algum; um semióforo tem apenas o significado de que é o vetor sem ter a mínima utilidade; mas existem também objetos que parecem ser ao mesmo tempo coisas e semióforos. Note-se que tanto a utilidade quanto o significado pressupõem um observador, porque não são senão relações que, por intermédio dos objetos, os indivíduos ou grupos mantêm com os seus ambientes visíveis ou invisíveis. Posto isto, nenhum objeto é ao mesmo tempo e para um mesmo observador uma coisa e um semióforo. Porque é uma coisa só quando é utilizado, mas então ninguém se diverte a decifrar-lhe o significado, e quando o faz, a utilidade torna-se puramente virtual. Embora coexistindo uns com os 
outros, os traços da forma que permitem que um objeto seja útil e aqueles que o fazem um portador de significado sugerem dois comportamentos diferentes e reciprocamente exclusivos.

Para Baudrillard (2002), todo objeto apresenta duas funções: a de ser utilizado e a de ser possuído, as quais encontram-se em ordem inversa uma em relação à outra. Para este autor, um objeto utilizado no nosso cotidiano - por exemplo, uma geladeira, que tem o propósito de refrigerar - devolve o homem ao mundo, por meio de uma mediação prática. Já o objeto puro, privado de sua função ou abstraído de seu uso, passa a ser qualificado pelo indivíduo e torna-se objeto de coleção. O primeiro, estritamente prático, toma um estatuto social; o segundo, não mais especificado por sua função, toma um estatuto subjetivo.

O meio habitual conserva um estatuto ambíguo: nele o funcional desfaz-se continuamente no subjetivo, a posse mistura-se ao uso, em um empreendimento sempre carente de total integração. A coleção, ao contrário, pode nos servir de modelo, pois é nela que triunfa este empreendimento apaixonado de posse, nela que a prosa cotidiana dos objetos se torna poesia, discurso inconsciente e triunfal (Baudrillard, 2002, p. 95).

Segundo Ribeiro (2010), quando o colecionador retira de um objeto seu valor de uso e associa a ele um valor simbólico, está atribuindo um caráter de excepcionalidade a esse objeto. Para esta autora, as coleções apresentam em si valores imputados pelos colecionadores, os quais, ampliados e vinculados às construções coletivas, recuperam as lembranças de um determinado grupo social e refletem os valores das sociedades em que estão inseridos. Segundo a sua compreensão, um colecionador é sempre um interlocutor a presentificar a memória de um indivíduo ou de um grupo, lutando contra a dispersão das coisas e o esquecimento delas.

Para Suano (1986), o colecionismo é uma prática quase tão antiga quanto a existência do homem. $\bigcirc$ ato de recolher objetos e coisas de diferentes lugares representaria juntar pedaços de um mundo que se pretende compreender e ao qual se deseja pertencer ou dominar. Uma coleção reflete simultaneamente a realidade/história de uma parte do mundo onde foi constituída e também daquele indivíduo ou da sociedade que a coletou e a converteu em coleção.

Na visão de Lopes (2009, p. 12):

\begin{abstract}
As origens longínquas dos museus estão associadas ao fenômeno social do colecionismo, sendo os gabinetes renascentistas os marcos fundamentais do que foram os processos de consolidação ao longo dos séculos XVII, XVIII e XIX de alguns dos aspectos básicos do perfil dessas instituições, que se mantêm até nossos dias.
\end{abstract}

Ainda na compreensão desta autora, os objetos recolhidos aos gabinetes de curiosidades formavam semióforos, pois eram subtraídos de seu contexto original e ressignificados, perdendo sua utilidade e passando a representar o invisível.

As viagens que se multiplicam a partir do século XV deslocam as fronteiras do invisível e atingem locais até então impensados, levando dos novos mundos para os gabinetes dos príncipes e sábios não só mercadorias altamente lucrativas, mas também todo um novo saber (Lopes, 2009, p. 12).

Segundo Delicado (2009), o que se desejava exibir era um microcosmo do excêntrico, do peculiar e do incomum, constituído pelos exemplares provenientes das artes mecânicas, químicas, dos diversos espécimes botânicos, das armas, de monumentos e de antiguidades.

Para Schwarcz (2008), a criação de museus no século XVIII, na Europa, exemplificados pelos Museu do Louvre (1773) e Museu do Prado (1783), acontece em caráter estritamente comemorativo: "Essas primeiras instituições, mais conhecidas como cabinets de curiosité, eram, como o termo parece indicar, formadas antes para expor objetos à admiração pública do que pensadas enquanto espaços para o ensino e pesquisa científicos" (Schwarcz, 2008, p. 68).

De acordo com Possas (2005), o ato de colecionar transforma-se em entendimento acerca de tudo o que existe no mundo. A criação dos gabinetes de curiosidades

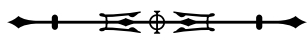


da Europa, tão em voga nos séculos XVI e XVII, demonstra preocupação com a memória, bem como necessidade de criação de mecanismos voltados ao não esquecimento. Esses gabinetes, a princípio, revelavam apenas o desejo de juntar objetos vindos de lugares remotos e desconhecidos, e se apossar deles, sem uma preocupação clara em classificar e nomear o que se amealhava.

Ainda conforme Schwarcz (2008, p. 68), somente a partir do século XIX são criados os museus etnográficos,

[...] instituições dedicadas à coleção, preservação, exibição, estudo e interpretação de objetos materiais. A curiosidade renascentista que havia marcado a exploração do Novo Mundo e do Oriente encontrava aconchego nesses estabelecimentos, que se firmavam enquanto lares institucionais de uma antropologia nascente.

Apesar de somente no século XIX ter sido criado oficialmente o primeiro museu no Brasil, o Museu Real (atual Museu Nacional), instituído em 1818, o precedente deste órgão foi a antiga Casa de História Natural, mais conhecida como Casa dos Pássaros, denominada desta maneira por conta da grande quantidade de aves empalhadas, a qual foi concebida em 1784, pelo vice-rei D. Luiz de Vasconcellos e Sousa, e por mais de vinte anos colecionou, armazenou e preparou produtos naturais e adornos indígenas para enviar a Lisboa (Lopes, 2009).

Com o falecimento de Francisco Xavier dos Pássaros, mais de duas décadas após a criação da Casa de História Natural, todas as coleções pertencentes a esse museu foram encaixotadas e entregues à vigilância extramuros dos dois ajudantes de Costa Barradas, então inspetor desta instituição, os quais nunca mais puseram os olhos no quarto onde as haviam emparedado e cuja entrada lhes foi formalmente vedada. Era o sarcófago no qual se decidiu por bem sepultar os restos mortais daquele mal vingado e tão cedo asfixiado começo do nosso primeiro museu (Netto, 1870 apud Papavero \& Teixeira, 2013).

Em 22 de junho de 1813, pela decisão de número 20, o príncipe regente $D$. João determinou a extinção de todos os cargos da Casa dos Pássaros, recomendando, ainda, que todos os produtos naturais fossem transferidos para a Academia Real Militar (ARM):

\begin{abstract}
Constando na real presença de Sua Alteza Real o Príncipe Regente Nosso Senhor a pouca utilidade que se tira da despesa feita com os empregados no denominado Museu; foi o mesmo Senhor servido ordenar, que se hajam por extintos os diferentes empregos de semelhante repartição, cessando os ordenados e vencimentos das pessoas a ela adidas, e sendo-lhes pago o que se lhes estiver devendo. Outrossim, foi o mesmo Senhor servido ordenar, que sejam entregues à Academia Real Militar todos os produtos naturais que ali se acharem e tudo quanto pertencer à Real Fazenda, expedindo-se as ordens a esse fim necessárias (Brasil, 1813, p. 26).
\end{abstract}

O prédio da Casa dos Pássaros foi derrubado para dar lugar à construção do edifício do erário. Todos os móveis e produtos existentes, entre os quais as peles de pássaros, os exemplares de insetos e de alguns mamíferos, foram armazenados em caixões e guardados por um período aproximado de um ano, quando, então, foram transferidos, por ordem do tenente-general Napion, para o Arsenal de Guerra. A coleção mineralógica, conhecida como Coleção Werner, foi armazenada junto a esse material (Lopes, 2009).

Mais tarde, no ano de 1816 [...] como fosse inconveniente, para os estudantes a distância em que se achava colocado este pequeno gabinete de ciências físicas e naturais, confiado então à direção do próprio lente de mineralogia, Fr. José da Costa Azevedo, transportaram-no para a Academia, ficando apenas no Arsenal o resto da coleção ornitológica da antiga Casa de História Natural (Netto, 1870, p. 11-16 apud Papavero \& Teixeira, 2013, p. 203).

A coleção mineralógica, destinada aos estudos práticos dos alunos da Academia Real Militar, em 1810, denominada de Coleção Werner, foi comprada por doze contos de réis de Karl Eugen Pabst von Ohain, assessor de minas da Academia de Freiberg, por volta de 1805. 0 destino dela seria o Museu de História Natural de Lisboa, e a ordem para sua compra partiu de Antônio de Araújo 
de Azevedo, Conde da Barca, que, à época, era ministro dos Estrangeiros e da Guerra (Lopes, 2009).

\begin{abstract}
A classificação e organização desta coleção foi anteriormente realizada pelo pai da mineralogia moderna, A. G. Werner, que lecionava em Freiberg. Este cientista foi o introdutor do primeiro sistema racional no mundo mineral. A coleção assim organizada, catalogada e ligeiramente descrita pelo maior mineralogista de sua época é conhecida ainda hoje por Coleção Mineralógica Werner. Contava originalmente cerca de 3.200 peças representando praticamente todas as espécies de minerais então conhecidas. Ainda possuía exemplares representativos das variações de cores, hábitos, formas etc. [...]. Quando a coroa portuguesa transferiu sua sede de Lisboa para o Brasil em 1807, veio com a vasta bagagem a grande coleção. A chamado do governo português, o Barão Ludwig von Eschwege chegou ao Brasil. A primeira incumbência do grande geólogo foi a instalação desta coleção. Seu destino inicial foi o Arsenal de Guerra, onde os alunos da antiga Academia Militar usavam-na nos estudos até a organização do novo Museu Real (Leinz, 1955, p. 2).
\end{abstract}

Segundo o relato de Lopes (2009), a coleção Werner foi integrada à ARM desde a sua fundação, em 1810, mas somente em 1816 foi transferida do Arsenal de Guerra para o prédio da Escola Militar, onde permaneceu até a sua transferência definitiva, em 1818, para o então recém-criado Museu Real. Frei José da Costa e Azevedo foi nomeado, por Carta Régia de 25 de março de 1815, lente proprietário da cadeira de História Natural da ARM; quase três anos após essa nomeação, tornou-se lente proprietário da cadeira de Mineralogia da ARM. Por esse tempo, assumiu também a administração do Gabinete de Produtos de Mineralogia e História Natural, que foi criado oficialmente na ARM.

\footnotetext{
A criação do Museu Real deu-se menos de cinco meses após a criação do Gabinete de Produtos de Mineralogia e História Natural na Academia Militar, e esse foi integralmente absorvido pela nova instituição, incluindo seu diretor. Frei José da Costa e Azevedo passou a ser o primeiro diretor do museu, ocupando o cargo até sua morte em 1822 (Figueirôa, 1997, p. 68).
}

De acordo com Lopes (2009), o decreto de criação do Museu Real, datado de 6 de junho de 1818, constituiu a base da nova instituição. Nele, além dos detalhes de compra das casas que passariam a abrigar o Museu, havia também uma autorização para que fossem transferidos os instrumentos, as máquinas e os gabinetes que estivessem em outros locais.

Com a transferência da coleção de minerais para - Museu Real, os alunos da Academia, para não serem privados do aprendizado prático, deslocavam-se até - Museu e, com a permissão do Frei José da Costa e Azevedo, que acumulava as funções de lente da Academia e diretor do Museu, obtinham o imprescindível contato com as amostras, situação que se manteve inalterada até a morte do frei, ocorrida em 1822. A partir desse momento, o acesso às coleções mineralógicas do Museu passou a ser dificultado aos alunos da Academia.

Em ofício da Junta Diretora da Academia Militar, datado de 23 de março de 1824, há solicitação a João Gomes da Silveira Mendonça, ministro dos Negócios da Guerra, para que fossem cedidas à Academia amostras de minerais com duplicatas no Museu, para que as aulas práticas de Mineralogia tivessem a sua continuidade. Na observação de Moreira (2014, p. 157):

\begin{abstract}
Percebe-se, por essa citação, como o ensino experimental não era considerado prioritário. Além de toda a coleção de minerais ter sido retirada da Academia Real Militar, o que deixou o gabinete de mineralogia da instituição desprovido de qualquer tipo de mineral, ao solicitar a doação de alguns exemplares o Diretor se restringe aos mais comuns e, mesmo assim, aquele que houvesse em duplicata. Assim, o Diretor da Academia Real Militar fez uma solicitação de parte de um material que já havia sido da própria Academia, e o fez de forma acanhada e submissa. Pode-se concluir que, por parte das autoridades governamentais, a exposição do material no Museu era considerada mais importante que o aprendizado prático dos alunos.
\end{abstract}

Essas amostras constituem o núcleo inicial da coleção de minerais da ENE.

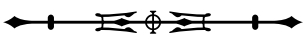


Em ofício de 8 de abril de 1828, enviado ao Sr. Pedro de Araújo Lima, ministro e secretário de Estado dos Negócios do Império, pela direção do Museu Nacional e Imperial, referindo-se à solicitação de doação de uma coleção mineralógica em favor da Academia, a orientação foi de que não se doasse, mas que se cedesse em empréstimo, até que no ambiente do Museu pudessem ser ministradas as aulas das Ciências da Observação aos alunos da Academia².

Percebemos, nesses dois documentos, produzidos em um intervalo de quatro anos, como as recomendações são divergentes. No primeiro exemplo, as aulas no Museu, permitidas e até ministradas por Frei José da Costa e Azevedo, foram consideradas contrárias à lei e ao costume; no segundo exemplo, no entanto, a recomendação é de que as amostras minerais fossem cedidas em forma de empréstimo, e não em doação, até que possam se estabelecer essas mesmas aulas no espaço do Museu.

De toda forma, a discussão mais premente e que constitui o cerne deste artigo é a tentativa de recompor a formação do acervo mineralógico da Escola Nacional de Engenharia (ENE), que hoje integra o patrimônio geológico do Museu da Geodiversidade, da UFRJ. As informações que dão contorno a este trabalho foram encontradas na bibliografia selecionada; em documentos primários, localizados tanto no Arquivo Nacional (AN) como na Seção de Memória e Arquivo do Museu Nacional (SEMEAR-MN); e em um antigo livro de registro de amostras da ENE, hoje em poder do IGEO/UFRJ.

A Academia Real Militar, criada por D. João VI em 1810, sucedendo a Real Academia de Artilharia, nasceu com uma dupla finalidade: preparar os oficiais para o Exército e os engenheiros para o Brasil (Mormêllo, 2010). A ARM, responsável pelo ensino das ciências exatas e de engenharia, transferiu-se, em abril de 1812, da Casa do Trem, onde funcionava o Arsenal de Guerra, para as novas instalações, ainda inacabadas, localizadas no Largo de São Francisco.
Com a instituição da ARM, o ensino militar no Brasil assumiu características científicas de um curso de nível superior (Moreira, 2014). Com a independência proclamada em 1822, a Real Academia Militar passou a se chamar Imperial Academia Militar; em 1832, foi rebatizada como Escola Militar da Corte; em 1840, o nome mudou para Escola Militar; e a partir de 1858 foi alterado para Escola Central.

Em 24 de maio de 1873, pela Lei de $n^{\circ} 2.261$, o governo passou a Escola Central para o Ministério do Império, separando, assim, o ensino militar do civil. Em 25 de abril de 1874, pelo Decreto n 5.600, a Escola Central mudou a sua denominação para Escola Politécnica, recebendo novos estatutos e passando a ser frequentada somente por alunos civis (Brasil, 1874). Em pleno Estado Novo, dentro de um projeto de reforma universitária do governo do Presidente Getúlio Vargas, oficializado pela Lei no 452, de 5 de julho de 1937, a Escola Politécnica recebeu nova denominação, passando a integrar a Universidade do Brasil, como Escola Nacional de Engenharia (ENE) (Brasil, 1937; Bastos, 2016).

O acervo de minerais e de rochas da ENE foi constituído por várias coleções adquiridas por compra ou por doação ao longo de sua trajetória, em diversos períodos atravessados por ela e denominações que adquiriu no decorrer do tempo.

Figueirôa (1997) informa que Henri Gorceix, quando desembarcou em julho de 1874 no Rio de Janeiro, teve como primeira incumbência a realização de uma viagem ao Rio Grande do Sul. Dela, ele retornou com uma excelente e já formada coleção de minerais, e teria cedido ao acervo da Escola Politécnica as duplicatas dessa coleção:

Em 1876, o Gabinete de Mineralogia e Geologia contava 750 amostras de minerais (sendo 82 de Minas Gerais e 79 do Rio Grande do Sul, colhidas e doadas por Henri Gorceix, e o restante adquiridas no estrangeiro), 2.939 amostras de rochas (quase todas da Coleção Kramer), 300 fósseis e mais 668 modelos cristalográficos de madeira (Figueirôa, 1997, p. 112).

2 Ofício de 8 de abril de 1828. Livro de Ofícios - Correspondência Oficial 1819/1842. p. 48-49. Seção de Memória e Arquivo do Museu Nacional, da Universidade Federal do Rio de Janeiro (SEMEAR-MN-UFRJ), Rio de Janeiro. 
Importante registrar que, em 1978, a Escola Nacional de Engenharia, da UFRJ, remeteu para o Arquivo Nacional documentos produzidos ao longo da trajetória da Escola. acervo então constituído foi dividido em duas séries, denominadas de Série Educação-Ensino Superior e Série Guerra-Escolas, representadas pelas siglas IE (Educação) e IG (Guerra).

A consulta aos documentos primários permitiu uma visão mais abrangente a respeito da composição desse acervo. Alguns poucos processos de aquisição estavam fartamente documentados, outros nem tanto.

Em 4 de maio de $1859^{3}$, o opositor substituto da aula de Geologia e Mineralogia, Miguel Antonio da Silva, comunicou ao diretor da Escola Central, Marechal de Campo Firmino Herculano de Moraes Ancora, a doação de amostras minerais, oferecidas ao Gabinete da Escola pelo Dr. Charles Joseph Frédéric Carron Du Villards (18011860), médico oftalmologista, pedindo que em nome da mesma fosse feito agradecimento ao ilustre doador.

Outra referência à doação de uma coleção de minerais ao Gabinete de Mineralogia e Geologia da Escola foi comprovada em ofício datado de 5 de setembro de 1868, remetido ao conselheiro Barão de Muritiba, ministro e secretário de Estado dos Negócios da Guerra Manuel José Vieira Tosta, e assinado por José Maria da Silva Bitencourt, marechal do Exército, professor e diretor da Escola Central:

Ilm $^{\circ}$ Exm Sr Cons. Barão de Muritiba, Ministro e Secretário de Estado dos Negócios da Guerra. Tenho a honra de levar ao conhecimento de $\mathrm{V}$. Ex $x^{\mathrm{a}}$ que foram recolhidas ao Gabinete de Mineralogia e Geologia desta Escola quarenta amostras de minerais do Brasil oferecidas pelo Bacharel José de Saldanha da Gama Filho ao mesmo Gabinete ${ }^{4}$. conselheiro João José de Oliveira Junqueira, que, à época, ocupava o cargo de ministro e secretário de Estado do Negócio de Guerra, com um parecer da comissão composta por lentes da Escola sobre a conveniência ou não em se adquirir por compra a coleção de amostras minerais de Thomas Rodenas, que as oferecia pelo valor de 7:000\$000.

Coleção de Minerais argentíficos do Sr. Thomas Rodenas. Esta coleção contém 140 amostras, sendo as mais importantes de prata nativa, sulfureto de arsênico e prata, cloretos [...], bromuretos [...] e sulfuretos de prata. São poucas de sabido valor mineralógico por causa da perfeição dos cristais. As outras, na maior parte grandes, são de espécies que se encontram com frequência em muitos lugares, de modo que pouco mais valem do que o valor intrínseco. $O$ valor da quantia de prata contida em todas as respectivas amostras pode se computar aproximadamente 2:000\$000. Há uma série de amostras auríferas que, contudo, para o Brasil não tem muito valor porque nele encontram-se milhares de variedades. As amostras de minerais de cobre são escolhidas, porém essas são de custo moderado. Conquanto a coleção seja muito útil para estudo e a desejar que a Escola Central a adquira para este fim, a Comissão é de parecer que não se deve despender com ela maior quantia que seis a oito contos, porque não convém que para uma especialidade se distraia maior soma de dinheiro que deve ser também aplicado a outras que são igualmente indispensáveis, como o de completar a coleção geológica, e principalmente na parte paleontológica que ainda está muito em princípio, mesmo os minerais ainda muitos há por comprar para completar a respectiva coleção. Se, pois, o proprietário fizer proposta para vender as 140 amostras à Escola, dentro do limite assinado, a Comissão insiste sobre a conveniência de comprá-la para a Escola, quando não, ela lembra a oportunidade de se pôr à disposição da Escola essa quantia, para por ocasião da Exposição Internacional de Viena, poder-se fazer a aquisição de amostras que ali se apresentarão, trocando outras por produtos do Brasil ${ }^{5}$.

Em 9 de agosto de 1872, José Maria da Silva Bitencourt, diretor da Escola Central, acusou o recebimento Sr. José Maria da Silva Bitencourt, enviou um ofício ao

3 Ofício datado de 4 de maio de 1859. Vale registrar que a relação anexada a este documento apresenta um total de 34 amostras. Arquivo Nacional, IG3-14, Rio de Janeiro.

4 Ofício datado de 5 de setembro de 1868. Arquivo Nacional, IG3-21, Rio de Janeiro.

5 Ofício datado de 30 de julho de 1872. Arquivo Nacional, IG3-22, Rio de Janeiro.

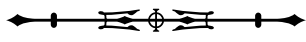


das cento e quarenta amostras de minerais da coleção Rodenas, enviadas ao Gabinete de Mineralogia da Escola (Figuras 1A e 1B). No dia seguinte, em 10 de agosto de 1872, o diretor da Escola Central comunicou o envio da conta ao ministro dos Negócios de Guerra, pela compra desta coleção feita pela Escola.

Avançando um período de nove anos, em 17 de agosto de 1881, encontramos um ofício do diretor da Escola Politécnica (EP), Ignacio da Cunha Galvão, ao conselheiro Barão Homem de Mello, atestando a necessidade de aquisição de diversos objetos para os gabinetes da Escola, incluindo duas coleções mineralógicas.

Com o Ofício n 27 de 30 de março do corrente ano, tive a honra de levar à presença de $\mathrm{V}$. Ex o orçamento das despesas a fazerem-se com a aquisição de vários objetos para os gabinetes desta Escola, entre os quais figuravam duas coleções mineralógicas: uma pertencente ao falecido Conselheiro Miguel Antonio da Silva avaliada em 1:500\$000 e outra do Engenheiro Halfeld, avaliada em 3:000\$000. Determinando V. Ex $x^{a}$ que fosse remetida à Secretaria uma relação das amostras que constituíam aquelas coleções, e achando-se na Escola somente a primeira coleção mencionada, aguardava o Lente da cadeira que chegasse a segunda, a fim de fazer a relação de ambas. Demorando-se, porém, a remessa dessa segunda coleção, organizou o Lente o catálogo da primeira sobre cuja aquisição insiste com urgência. Junto tenho a honra de remetê-la a $\mathrm{V}$. Ex $x^{\mathrm{a}}$ e oportunamente remeterei a da Coleção Halfeld, cuja aquisição, aliás, a vista da exiguidade de verba respectiva, talvez tenha que ser adiada para o exercício financeiro próximo ${ }^{6}$.

Em 3 de setembro de 1881, o mesmo diretor da Escola Politécnica enviou ao ministro e secretário de Estado dos Negócios do Império um ofício, solicitando o pagamento à viúva do conselheiro Miguel Antonio da Silva pela compra de uma coleção de minerais, e se queixou da verba insuficiente para outras aquisições destinadas aos Gabinetes da Escola:

Peço a V. Ex a que se digne dar suas ordens para ser paga pelo Tesouro Nacional a $\mathrm{Sr}^{\mathrm{a}}$ Maria Candida de Sepúlveda e Silva, viúva do Conselheiro Miguel Antonio da Silva, a quantia de 1:500\$000, importância de uma coleção de amostras de minerais conforme consta da inclusa conta em duplicata, comprada para o Gabinete de Mineralogia e Geologia, de conformidade com a autorização contida no Aviso no 25 de agosto próximo findo. [...] A verba votada para
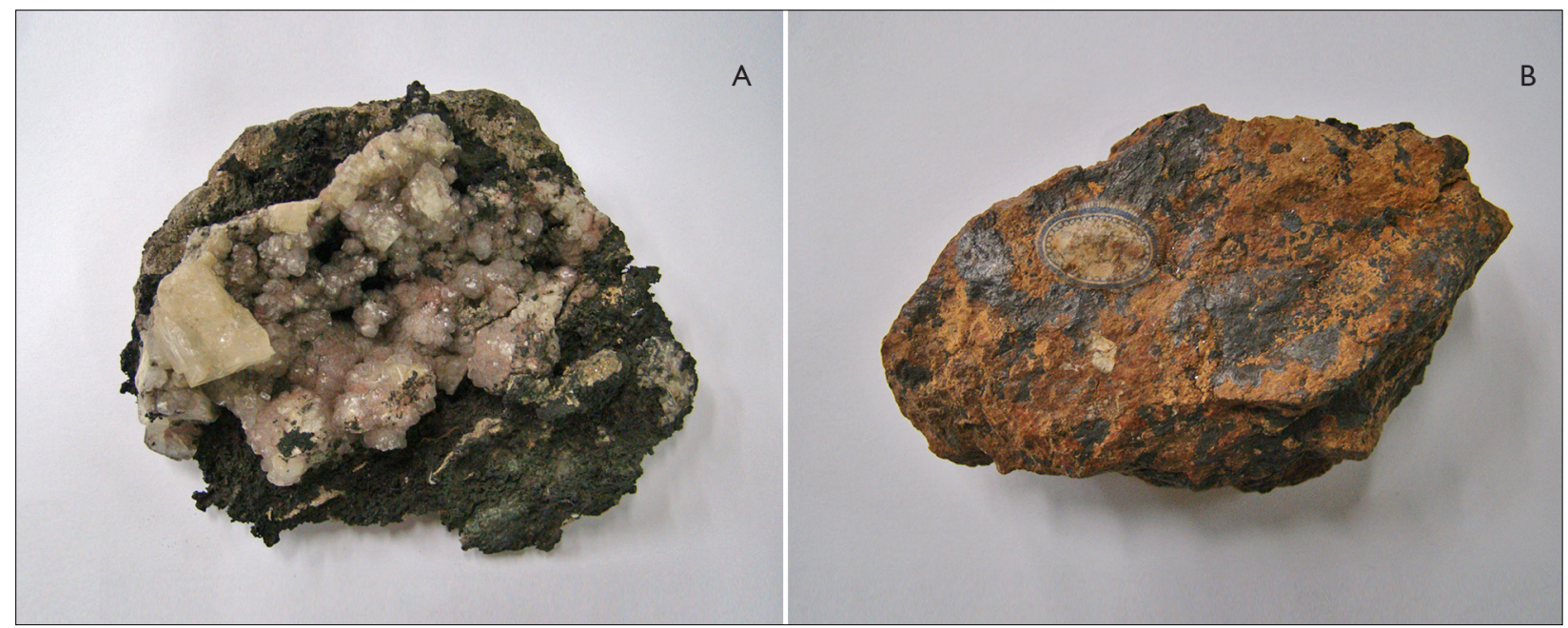

Figura 1. Amostra da coleção Thomas Rodenas: A) cobre nativo e calcita, procedentes de Cerro do Pazco (Peru); B) prata proveniente do Chile. Destaque para lastro original da antiga Escola Politécnica. Foto: Cícera Neysi de Almeida.

6 Ofício datado de 17 de agosto de 1881. Arquivo Nacional, IE3-83, Rio de Janeiro.

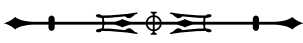


extraordinários e eventuais inclusive compra e conserto de móveis, que é de 2:000\$000, étambém insuficiente, atenta a necessidade de montar os novos gabinetes criados; tendo sido preciso sustar a execução da despesa autorizada com vitrinas indispensáveis para o Gabinete de Mineralogia, o qual tem de continuar ainda este ano, com as interessantes coleções quase inutilizadas por não poderem ser convenientemente expostas, e ficando por atender as necessidades dos gabinetes de Engenharia Civil, Química Orgânica, Metalurgia e Exploração de Minas. Rogo, portanto, a V. Exa com o maior empenho, se digne no próximo orçamento reforçar estas três verbas [...] a fim de que não pare o salutar progresso que tem tido os gabinetes da Escola ${ }^{7}$.

Com a compra da coleção do conselheiro Miguel Antonio da Silva concretizada, ainda faltava realizar a aquisição da coleção Halfeld para o gabinete mineralógico da Escola. Na data de 3 de novembro de 1881, o lente Oscar Nerval Gouvêa escreveu uma carta ao diretor da Escola, Ignacio da Cunha Galvão, solicitando não só a compra da coleção Halfeld, como também a de uma coleção paleontológica. Apesar deste artigo estar voltado exclusivamente para coleções de minerais e de rochas que compõem o acervo da Escola Politécnica, a autora achou por bem incluir este documento na íntegra, por considerar - sendo profissional de um Museu de Geociências -, que esse registro seria pertinente:

Consultado por V. Exa sobre a proposta do geólogo holandês Casimiro Ubaghs relativa à aquisição de sua coleção paleontológica apresso-me em declarar a V. Ex a que a considero vantajosa pelo fato de possuírem numerosos e mui interessantes fósseis da fauna cretácea.

Cumpre-me, outrossim, fazer notar a V. Ex a que essa coleção apresenta sobretudo o interesse de completar por assim dizer a desta Escola, preenchendo aí a lacuna observada com referência aos [...] e quelônios tão importantes nos terrenos jurássico e cretáceo. Estas razões além do desejo de enriquecer o Gabinete de Mineralogia, Geologia e Paleontologia, aperfeiçoando, portanto, o ensino destas matérias no único curso de Ciências Físicas e Naturais que o Brasil possui me parecem suficientes para demonstrar a $\mathrm{V}$. Ex $\mathrm{x}^{\mathrm{a}}$ a necessidade de instar perante o Governo Imperial pelas vantagens dessa preciosa aquisição. $\bigcirc$ estudo das Ciências Físicas e Naturais como V. Exa perfeitamente reconhece não pode prescindir da observação dos fatos naturais e de experiências tendentes a reproduzi-los ou a facilitar a sua compreensão, e esse tem sido o alvo dos nossos esforços desde que ocupei a cadeira de Mineralogia e Geologia desta Escola. Na parte relativa à experenciar, já possuímos ou devem chegar brevemente aparelhos que não possuímos entre os quais cumpre mencionar goniômetros como o de Babinet, a moderna balança de Jolly para avaliar densidades, esclerômetros para o estudo comparativo da dureza dos minerais em lâminas cristalinas, finalmente o microscópio polarizante, a fim de analisar a microestrutura das rochas e melhor classificá-las por sua dureza interna. Entretanto, como ao lado das experiências devíamos desenvolver a observação pelo aperfeiçoamento do estudo descritivo dos minerais e rochas aumentando as nossas coleções, requeri há algum tempo ao Governo Imperial a aquisição da coleção Halfeld, hoje em mãos de um filho do Exm Senador Jaguaribe, o qual consta de 12 caixas de minerais quase todos do Brasil, contendo valiosíssimas amostras de ouro extraídas das minas exploradas em nosso país, coleção avaliada pelo proprietário atual apenas na quantia de 3:000\$000. Infelizmente, porém, a Escola Politécnica não possui esses interessantes minerais, visto que o proprietário ainda não resolveu a despender o elevado frete do transporte de Juiz de Fora para a Corte na incerteza do bom resultado dessa negociação e apenas com o fim de me permitir a elaboração da lista ou relação completa de todas as amostras, segundo a decisão do governo por ocasião da proposta ${ }^{8}$.

A resposta veio rápida: em 7 de novembro de 1881, o diretor da Escola Politécnica reportou-se, em ofício, ao conselheiro Manoel Pinto de Souza Dantas, ministro e secretário de Estado dos Negócios da Justiça e interino do Império, documento no qual reconhece a importância das coleções, entretanto as verbas para a Escola não comportam tais aquisições ${ }^{9}$.

\footnotetext{
Ofício datado de 3 de setembro de 1881. Arquivo Nacional, IE3-83, Rio de Janeiro.

8 Ofício datado de 3 de novembro de 1881. Arquivo Nacional, IE3-83, Rio de Janeiro.

9 Ofício datado de 7 de novembro de 1881. Arquivo Nacional, IE3-83, Rio de Janeiro.
}

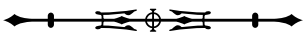


O lente Oscar Nerval de Gouvêa insiste no pedido de se adquirir a coleção Halfeld para o Gabinete da Escola. Em outro documento, datado de 21 de setembro de 1882, novamente recomenda ao diretor da Escola Politécnica a compra da coleção:

De acordo com o pedido feito para o Gabinete de Mineralogia e Geologia e aplicado pela Congregação desta Escola, em que se fundamentara a necessidade e vantagens da aquisição da Coleção Halfeld, pertencente ao Sr. Jaguaribe, venho comunicar a V. Exa que essa coleção se acha no dito Gabinete e que consta dos minerais que resumidamente enumero na lista que ora remeto a $V$. Exa . A organização dos catálogos detalhados, sendo assunto de um trabalho muito longo e minucioso, depende de análises que só convém fazer depois de adquirida a coleção, limitei-me a enumerar sumariamente os minerais que constam do ensaio de catálogo junto às amostras de que ela se compõe, podendo assegurar a $\mathrm{V}$. Ex $x^{a}$ que por sua extensão e importância, essa coleção poderá ser considerada como a mais completa que se conhece entre as formadas exclusivamente de minerais brasileiros. A necessidade de aumentar - Gabinete pela aquisição de amostras de minerais do Brasil, coleção que anualmente deverá progredir pelas excursões realizadas pelos alunos, já se fazia sentir a quem quer que visite as nossas coleções onde avultam minerais de países estrangeiros principalmente da Europa e do Chile, e onde poucos espécimes representavam a riqueza natural do nosso solo. Oficiando, pois, a V. Exa , que empenho a que se represente perante o Governo Imperial e com a necessária instância, a fim de não perder esta ocasião de beneficiar o ensino, fornecendo-lhe esses documentos, que outras coisas não são as Coleções em Ciências Naturais, em que se buscam ou que comprovam todas as ilações teóricas ${ }^{10}$.

Ignacio da Cunha Galvão, diretor da EP, remeteu ofício ao conselheiro Pedro Leão Veloso, ministro e secretário de Estado dos Negócios do Império, em 29 de setembro de 1882, confirmando a impossibilidade da aquisição da coleção por questão orçamentária da Escola ${ }^{11}$.

Finalmente, a compra da coleção Halfeld foi autorizada em 27 de outubro de 1882, sendo essa transação comprovada pelo ofício de Ignacio da Cunha Galvão, datado de 7 de novembro de 1882, solicitando ao conselheiro Pedro Leão Velloso o pagamento a Joaquim Nogueira Jaguaribe pela aquisição desta coleção. Segundo esse mesmo ofício, foi pago por essa coleção o valor de três contos de réis $(3: 000 \$ 000)^{12}$.

Em pasta datada de 9 de fevereiro de 1883, há um documento com a informação acerca da origem da verba usada na compra da coleção Halfeld.

\begin{abstract}
Verba donativos. Em vista da exiguidade das verbas do orçamento da Escola, V. Exm ${ }^{\circ} \mathrm{Sr}$. Ministro autorizou por conta da verba "donativos" as despesas para os serviços mais urgentes dos diversos gabinetes e aulas. Por conta dessa verba foi feita a aquisição para o Gabinete de Mineralogia e Geologia de interessante coleção mineralógica de Halfeld que compreende perto de 5.000 amostras. Autorização: 24 de outubro de 1882 - 3:000\$000 com a compra para o Laboratório de Mineralogia e Geologia da coleção organizada pelo Engenheiro Halfeld ${ }^{13}$.
\end{abstract}

Conforme Figueirôa (1997), a coleção Halfeld era composta por 4.679 amostras, agrupadas em seis seções. O destaque desta coleção eram os exemplares brasileiros, sobretudo os originários das minas de ouro de Minas Gerais (Figuras 2A e 2B).

Heinrich Wilhelm Ferdinand Halfeld (1797-1873) foi um engenheiro alemão, natural de Hanôver, que chegou ao Brasil em 1825 e se naturalizou brasileiro em 1840. Trabalhou na companhia de mineração São João d'el Rei, nas minerações que havia em Minas Gerais. Segundo documento encontrado no Arquivo Nacional, a coleção Halfeld assim se distribuía:

10 Ofício datado de 21 de setembro de 1882. Arquivo Nacional, IG3-84, Rio de Janeiro.

11 Ofício datado de 29 de setembro de 1882. Arquivo Nacional, IG3-84, Rio de Janeiro.

12 Ofício datado de 7 de novembro de 1882. Arquivo Nacional, IG3-84, Rio de Janeiro.

13 Documento datado de 9 de fevereiro de 1883. Arquivo Nacional, IG3-84, Rio de Janeiro. 
1a seção: Aurífera do Brasil - 179 amostras de ouro catalogadas, tudo indicando as proveniências que abrangem todas as minas exploradas no Brasil, como Morro Velho, Gongo Soco, Taquaryl e outras ainda não exploradas. $2^{\mathrm{a}}$ seção: Minerais diversos do Brasil - 335 amostras de minerais como piritos de ferro, calcários, ágatas e calcedônias, etc. $3^{\mathrm{a}}$ seção: Rochas Brasileiras: 130 amostras de diferentes rochas catalogadas, abrangendo gnaisse e suas variedades, xistos, calcários, conglomerados, etc. $4^{\mathrm{a}}$ seção: Minerais da Europa, Chile e México: 86 amostras catalogadas abrangendo minerais de ouro, prata, chumbo, cobre, etc. $5^{a}$ seção: Fósseis - 22 fósseis diversos, abrangendo os gêneros belemnites, nautilus, etc., um peixe fóssil e um dente de mastodonte. $6^{a}$ seção: Minerais não classificados 3.927 amostras de minerais e rochas brasileiras não classificadas (encerradas em 12 caixões) ${ }^{14}$.

Em poder do Departamento de Geologia, do IGEO/ UFRJ, há um antigo caderno de registro de amostras que pertenceram à Escola Politécnica, no qual 1.045 exemplares estão anotados, cada um com sua respectiva numeração, nome do mineral, proveniência e coletor. Não há, porém, nenhuma anotação no caderno que nos ajude a precisar com exatidão quando esse documento foi produzido, mas certamente foi nas primeiras décadas do século XX. Algumas das coleções descritas no caderno foram referenciadas no presente artigo, como as coleções Rodenas e Halfeld, mas o número de exemplares registrados é infinitamente mais reduzido do que a totalidade original da coleção, fazendo supor que esse caderno deveria ser o primeiro de uma série existente no assentamento das amostras em poder da ENE. A coleção Rodenas, que continha 140 exemplares, foi reduzida a 31, e a coleção Halfeld, com seus quase 5.000 itens, consta no caderno com somente 83 exemplares.

\section{IMPORTÂNCIA HISTÓRICA E CIENTÍFICA DA COLEÇÃO}

Como descrito anteriormente, a coleção de minerais e rochas da Escola Nacional de Engenharia tem sua origem vinculada ao episódio da transferência da coleção Werner para o recém-criado Museu Real, em 1818, fator determinante para que a Academia Real Militar iniciasse a formação de uma coleção mineralógica útil à ilustração e ao aprendizado aos seus alunos. $\bigcirc$ pedido de amostras minerais duplicadas feito no ano de 1828 pelo lente da cadeira de Química, Daniel Gardner, substituto de Frei José nas aulas de Mineralogia, ilustra bem essa preocupação.
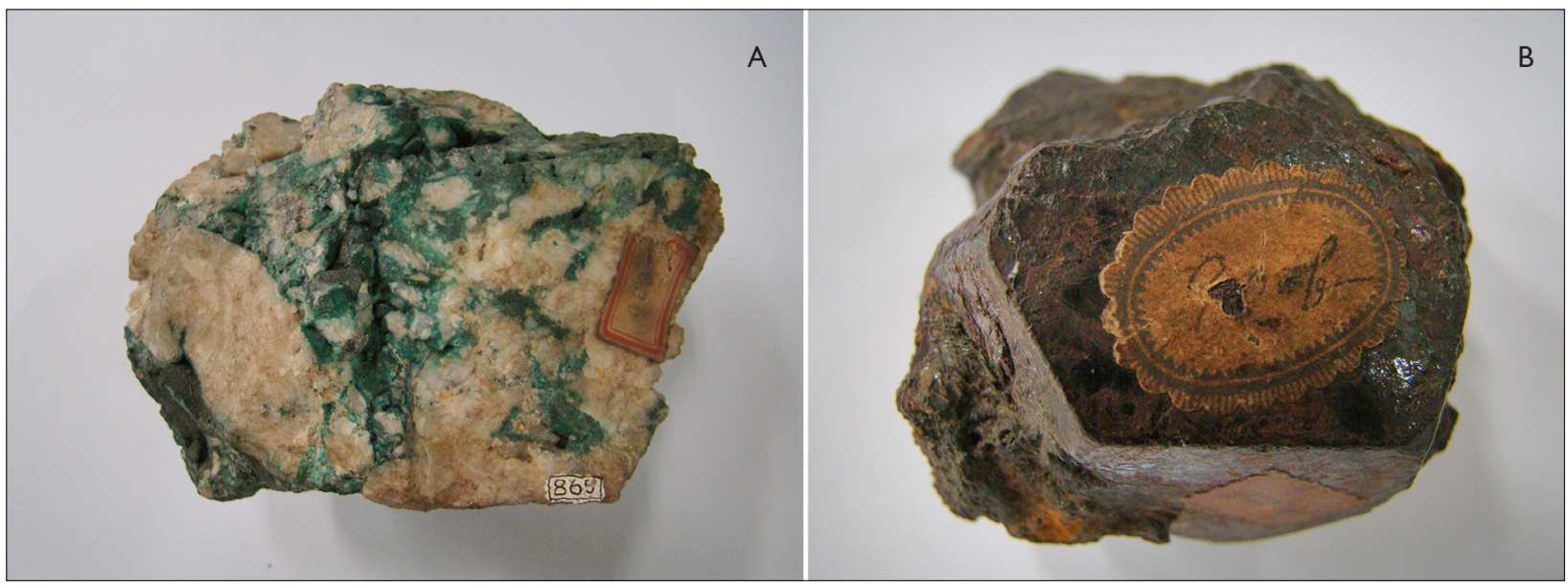

Figura 2. Amostra da coleção Halfeld: A) malaquita proveniente do estado de Minas Gerais. Destaque para o lastro em forma de etiqueta da Escola Nacional de Engenharia e para o lastro atual; B) pirita limonitizada proveniente de Minas Gerais. Destaque para o antigo lastro em forma de etiqueta. Fotos: Cícera Neysi de Almeida.

${ }^{14}$ Documento anexado ao ofício datado de 7 de novembro de 1882. Arquivo Nacional, IE3-84, Rio de Janeiro.

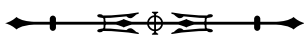


As coleções mineralógicas que originaram as coleções didático-científicas foram criadas com o objetivo de complementar as atividades teóricas. Em seu relatório de exercícios práticos, de 1877, o lente de Mineralogia da Escola Politécnica, Dr. Miguel Antonio da Silva, descreveu com alguns detalhes como se realizavam as aulas de campo ${ }^{15}$. Importante notar que, além da apreciação dos minerais e das rochas in situ, havia também a preocupação de prover o gabinete mineralógico da Escola com as amostras recolhidas. Para Figueirôa (1997), ainda que com caráter de ilustração da teoria, o certo é que o ensino prático passou a adquirir a cada dia mais importância na Politécnica do Rio de Janeiro.

Além da constante inquietação por formar um acervo mineralógico próprio, havia também uma preocupação permanente com a atualização e a manutenção dos gabinetes da Escola. Em ofício de 14 de junho de 1883, Ignacio da Cunha Galvão, diretor da Escola Politécnica, remete ao conselheiro Francisco Maciel, ministro do Império, cobrança relativa à aquisição de utensílios para o Gabinete de Mineralogia ${ }^{16}$. Na nota de compra do Armazém e Oficinas de Ótica e Instrumentos Científicos José Hermida Pazos, consta a seguinte relação:

1 coleção de lâminas de minerais destinadas ao estudo das propriedades óticas no aparelho de Solleil - 65\$000; 1 aparelho destinado a preparação de lâminas de rochas para microscópio polarizante e acessórios - 600\$000; 1 coleção de lâminas de minerais e rochas para estudo micrográfico - 78\$000; 1 coleção de lâminas de minerais para a apreciação da dureza do esclorômetro - 40\$000; 1 estojo de investimentos para estudos práticos da geologia contendo: um martelo, uma serrela, um clinômetro com régua de $2 \mathrm{~m}$ de comprimento, uma bússola e duas serras de diferentes dimensões - 540\$000; 1 goniômetro de aplicações - 50\$00017.
Na ótica de Figueirôa (1997), os professores da Politécnica também estavam atualizados no que se referia às aquisições da Biblioteca da Escola. Entre as obras de Mineralogia adotadas ${ }^{18}$, a autora cita "System of mineralogy", de Dana \& Brush (1875), e os "Sistemas Cristalinos de Naumann" (1872 apud Blake, 1899). Nos programas para o estudo da Mineralogia na Politécnica, a subdivisão adotada obedecia aos seguintes critérios: Morfologia Mineral (na qual se incluía a Cristalografia), Fisiologia Mineral (que abrangia o estudo das propriedades físicas e químicas) e Taxonomia Mineral (essencialmente Mineralogia Descritiva).

Quanto ao ensino teórico, a autora assinala a atualização dos conteúdos programáticos em relação à ciência que se fazia na época (ano de 1862), contemplando, por exemplo, os seguintes temas: cristalografia; determinação de minerais pelos caracteres pirognósticos; ensaios químicos; classificação e enumeração das principais espécies com referência à petrografia; composição de veeiros; geognosia envolvendo estudos petrográficos sobre as principais espécies paleontológicas; condições de acamamento, perturbações de equilíbrio da crosta terrestre; ações ígneas e aquosas; coralinas; terremotos; vulcões; rios e lagos; águas represadas; caracteres das principais formações.

Outros recursos empregados nas aulas de mineralogia, em apoio ao ensino prático e que aqui merece ser assinalado, eram os modelos de madeira. Usados em caráter pedagógico ainda na atualidade para a verificação da simetria externa dos minerais, estes modelos têm um papel particularmente importante na visualização dos conceitos inerentes à cristalografia (Amaral, 2011).

Apenas para ilustração, em ofício de 1825, assinado pelo então diretor do Museu Nacional e Imperial, Sr. João da Silveira Caldeira, e remetido ao Sr. Estevão Ribeiro de

15 Documento datado de 20 de abril de 1877. Arquivo Nacional, IE3-262, Rio de Janeiro.

16 Ofício datado de 14 de junho de 1883. Arquivo Nacional, IE3-85, Rio de Janeiro.

17 Ofício datado de 14 de junho de 1883. Arquivo Nacional, IE3-85, Rio de Janeiro.

18 Os títulos das obras aqui citadas por Figueirôa (1997, p. 114) têm como fonte o catálogo da biblioteca da Escola Politechnica, de 1882. Ressalvas: O título "System of mineralogy", de 1875, é de autoria de Dana \& Brush, e o título "Sistemas cristalinos de Naumann", de 1872, remete às "Apostillas para estudo dos systemas crystalinos de Naumann", 1872, de autoria de José de Saldanha da Gama, $2^{\circ}$, citado por Augusto Blake no "Diccionário Bibliographico Brazileiro", 1899, v. 5, p. 177.

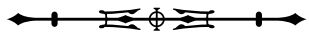


Rezende, ministro e secretário de Estado dos Negócios do Império, a autora encontrou uma descrição da utilização e relevância desses modelos no que se refere à prática do ensino da cristalografia.

Achando-se arranjado a coleção mineralógica na Europa pela classificação do célebre e nunca assaz louvado Abade Haüi, classificação esta que se funda inteiramente sobre a composição química e sobre as formas poliédricas, que os diferentes produtos mineralógicos a cada [...] apresentam, e para completar no Museu esta bela parte da História Natural tão útil pelos serviços que de contínuo faz as artes, e pelas relações íntimas que tem com a química e com a geometria, sendo necessário uma série completa de modelos em madeira de diferentes variedades e formas cristalinas, segundo as medidas e ângulos dados pelo sábio autor do Tratado de Mineralogia assim como uma coleção completa da marcha dos decrescimentos relativos às diferentes formas secundárias, tem a liberdade de levar a V. Ex. para se dignar pôr os pés de S.M.I. que torna-se extremamente necessário e útil a este estabelecimento estes modelos, sem os quais os estudantes não poderão dar passos avantajados no estudo desta ciência $[\ldots]^{19}$.

No último quartel do século $\mathrm{XIX}$, mais especificamente a partir de 1870, o Brasil conquistou avanços em atividades científicas, como nunca visto antes. Dentro desse contexto, o país experimentou uma série de iniciativas no âmbito científico-cultural, que envolveram tanto a criação de novos espaços institucionais quanto a reformulação dos preexistentes (Figueirôa, 1997).

O século XIX foi um período de grande efervescência científica e de progresso tecnológico; e em consequência dessa nova ordem, ocorreram mudanças significativas no padrão de formação e transmissão de conhecimentos. No que diz respeito especificamente às coleções mineralógicas abordadas nesse estudo, quer tenham sido obtidas por compra, doação ou coletadas em trabalhos de campo, têm se revelado importantes registros do patrimônio geológico, que, inseridos no espaço do museu, produzem novas perspectivas em termos comunicacionais, dilatando, desse modo, a abrangência educacional, cultural e científica dessas coleções.

\section{O ACERVO DE MINERAIS E ROCHAS E O MGEO}

O Museu da Geodiversidade (MGeo), criado em 2007, mas só inaugurado em 2008, em comemoração aos 50 anos do curso de Geologia, está localizado nas dependências do Instituto de Geociências (IGeo), da UFRJ, na Ilha do Fundão, possuindo uma das maiores coleções de fósseis do país, com cerca de 20 mil itens em seu acervo, constituído também por minerais, rochas, fotografias, mapas, documentos, objetos histórico-científicos e livros raros. Ele está dividido em coleções variadas, a saber: de minerais; de rochas; de fósseis; de icnofósseis; didática; de reconstituiç̧ões (referente a reconstituições artísticas de animais extintos); arqueológica e histórico-científica (Barroso et al., 2008).

A criação de um museu da geodiversidade no espaço do Instituto de Geociências, da UFRJ, foi motivada não somente pela comemoração dos 50 anos do curso de Geologia no Brasil, mas também pela possibilidade de melhor compreensão e consequente popularização das informações acerca das ciências geológicas junto à sociedade. Existia, ainda, preocupação com a integridade física e a segurança desses conjuntos, que poderiam se deteriorar e se perder ao longo do tempo, causando enorme prejuízo ao desenvolvimento acadêmico dos alunos, ao conhecimento em geociências e à sociedade em geral.

Para Castro (2014), a comunidade geocientífica começou a se empenhar na divulgação do patrimônio geológico quando percebeu que grande parcela da sociedade estava distante dos conceitos relacionados à Geologia. Referindo-se especificamente às coleções mineralógicas, Silva et al. (2008) observam que, para uma formação acadêmica de qualidade na área das ciências geológicas, são fundamentais a criação e a manutenção de acervos técnicos, didáticos e históricos de minerais e de rochas.

19 Ofício datado de 13 de maio de 1825. Livro de Ofícios-Correspondência Oficial 1819/1842, p. 14. SEMEAR-MN-UFRJ, Rio de Janeiro. 
A possibilidade da existência de uma cultura universitária presume, portanto, a necessidade de difundi-la, torná-la acessível aos não universitários, de maneira a trabalhar também no fortalecimento da universidade como lócus portador de características, peculiares e privilegiadas, da sociedade atual (Ribeiro, 2013).

Quanto à composição do acervo de minerais e rochas do MGeo, este é formado por variadas coleções, entre as quais ganham destaque as amostras trazidas da Escola Nacional de Engenharia (ENE) e as da Faculdade Nacional de Filosofia (FNFi).

Por meio de vestígios de antigas etiquetas, constatamos que foram incorporadas aos acervos da ENE e da FNFi coleções mineralógicas comerciais, assim distribuídas: coleções Krantz, Emílio Schupp \& Cia. e Anette Gutknecht (ENE) e Coleção W. D. Johnston Jr. (FNFi). No que concerne especificamente ao acervo mineralógico da ENE, não apenas integraram esse conjunto coleções comerciais, mas também outras, adquiridas por meio de compra ou de doação, como já descrito neste artigo.

Ainda compõem o acervo de minerais e rochas do MGeo a Coleção Ward's, adquirida por compra; a Coleção de Geologia Econômica, organizada pelo professor Jacques Pierre Cassedane (aposentado do Departamento de Geologia/UFRJ); a Coleção de Minerais Metálicos representantes de minas brasileiras; e as amostras do Laboratório Didático de Mineralogia, formando um conjunto de aproximadamente quatro mil exemplares.

\section{A INCORPORAÇÃO DA COLEÇÃO DA ENE AO MGEO}

Os museus, para além da coleta, da seleção, do registro, da documentação e da exibição de peças, preocupam-se com a salvaguarda de seus acervos, com a integridade física de suas coleções. Na compreensão de Chagas (1994), a preservação não se justifica por si mesma, sendo necessário que, ao lado da preservação, seja instaurado o processo de comunicação.
Para Castro et al. (2011, p. 42),

os museus são fontes perenes de atualização ao longo do tempo e configuram-se como excelentes ferramentas para o embasamento das informações a serem transferidas em todas as áreas do conhecimento. Nos museus científicos, as ciências e as tecnologias são apresentadas, refletidas e desmitificadas, tornando a informação acessível à sociedade.

Cury (1999) compreende o processo de musealização como uma valorização seletiva, mas contínua, no conjunto de ações que visam à transformação do objeto em documento e voltadas à sua comunicação. Esse processo tem seu início ao selecionarmos um objeto dentro de seu contexto, e é finalizado quando o apresentamos ao público, seja por meio de exposições, de atividades educativas etc.

Na visão de Santos \& Loureiro (2012, p. 51),

como estratégia de preservação, a musealização aponta para essas duas direções, objetivando não apenas garantir a integridade física de uma seleção de objetos, mas também promover ações de pesquisa e documentação voltadas à produção, ao registro e à disseminação das informações a eles relacionadas, com vistas à transmissão a gerações presentes e futuras.

Quanto à incorporação da coleção de minerais e rochas da ENE e de outras mais antigas ao IGEO/UFRJ, não foram encontrados documentos que respaldassem a informação verbal que circula entre docentes e técnicos de longa trajetória profissional, ao afirmarem que elas vieram transferidas (de maneira negligenciada) do velho prédio do Largo de São Francisco, onde funcionou a ENE, à época do regime militar.

A preservação de uma coleção de minerais é fundamental para manter um registro, muitas vezes o único, de depósitos e afloramentos que definem a história da Terra (Almeida et al., 2014). Faculdades, universidades e museus que têm patrocinado a criação de coleções geológicas também possuem a responsabilidade de mantê-las, sendo que esta obrigação inclui a manutenção física e a acessibilidade para pesquisa científica e educação (Howie, 1992). 
Para atender a todas estas demandas, concluiu-se que, nas dependências do IGeo, um museu seria o melhor modelo institucional de pesquisa, de preservação e de divulgação. Nesse âmbito, o Departamento de Geologia/ IGEO/UFRJ vem realizando um trabalho com o objetivo de tornar visível e de permitir o acesso ao seu acervo de minerais e rochas, em grande parte fechado em armários e distribuído em salas trancadas, sendo apenas colocados em disponibilidade os exemplares expostos no MGeo ou no Laboratório Didático de Mineralogia. Em 2008, foi iniciado um trabalho de reorganização das diversas coleções de minerais e rochas que compõem o acervo do Museu.

A respeito do processo de tratamento técnico (higienização, identificação, classificação, registro, acondicionamento, organização física e comunicação), as amostras que compõem o acervo de minerais e rochas do MGeo estão sendo organizadas para que se tornem acessíveis e utilizadas como fonte de consulta e de pesquisa, tanto pelo público especializado (corpo docente e discente do IGeo e demais pesquisadores em geociências) quanto pelo público em geral (alunos da educação básica da rede pública e privada, além de outros visitantes).

Vale registrar que a organização dessas coleções está sendo feita por tipologia de jazidas, segundo o método de Routhier (1963), que classifica as jazidas minerais conforme o ambiente geológico nos quais estas foram formadas - a saber, ciclo exógeno (concentrações ligadas à superfície da crosta) e ciclo hipógeno (concentrações ligadas ao interior da crosta).

Acerca do tratamento e da disseminação informacional e em relação às ações de revitalização desse acervo, podemos incluir a criação de um banco de dados digital, que facilitará a consulta por acesso remoto às coleções mineralógicas, rompendo, assim, os limites impostos pela localização. Na organização dessas informações, os itens contemplados no banco de dados para cada amostra são: 1) nome do mineral; 2) número de registro; 3) variedade; 4) fórmula; 5) procedência; 6) coletor; 7) data da coleta; 8) origem histórica; 9) dimensões da amostra; 10) imagens (cada mineral é fotografado em diferentes ângulos, em um total de quatro imagens por mineral); 11) observações.

\section{CONCLUSÕES}

$\mathrm{Na}$ tentativa de restabelecer, por meio de documentos primários, a constituição da coleção mineralógica da Escola Nacional de Engenharia, seguiram-se as pistas apontadas aqui e ali no emaranhando de papéis que atravessou o tempo e que repousa nos arquivos públicos, à espera de ser revelado e interpretado. Vale observar que não existe no Instituto de Geociências nenhuma documentação referente às coleções mineralógicas, além do antigo livro de registro de amostras da ENE e das etiquetas (Figuras 3A e 3B) correspondentes às diversas coleções. A documentação disponível serve apenas para uma identificação sucinta das amostras, tais como o nome do mineral ou da rocha, sua proveniência e seu coletor. Essa economia de informações e tal carência de mais conhecimento acerca das coleções comprometem consideravelmente as atividades desenvolvidas pela equipe do museu.

Para Wanderley \& Ribeiro (2011), a não documentação das coleções de um museu o transforma em depósito de objetos; um museu que não tem acesso pleno às suas coleções não pode ser qualificado como uma instituição museológica.

Na concepção de Barbuy (2008, p. 35),

a organização da informação sobre os acervos de museus que denominamos como documentação museológica serve como base para todos os demais trabalhos institucionais, bem como para tornar a informação acessível a pesquisadores e públicos externos.

Segundo Loureiro (2008), a informação é um componente de suma importância para o desenvolvimento de toda e qualquer ação no âmbito do museu. Para este autor, os objetos/documentos musealizados não estão limitados unicamente por sua materialidade, pelo palpável, mas principalmente por seus contextos históricos e socioculturais. 


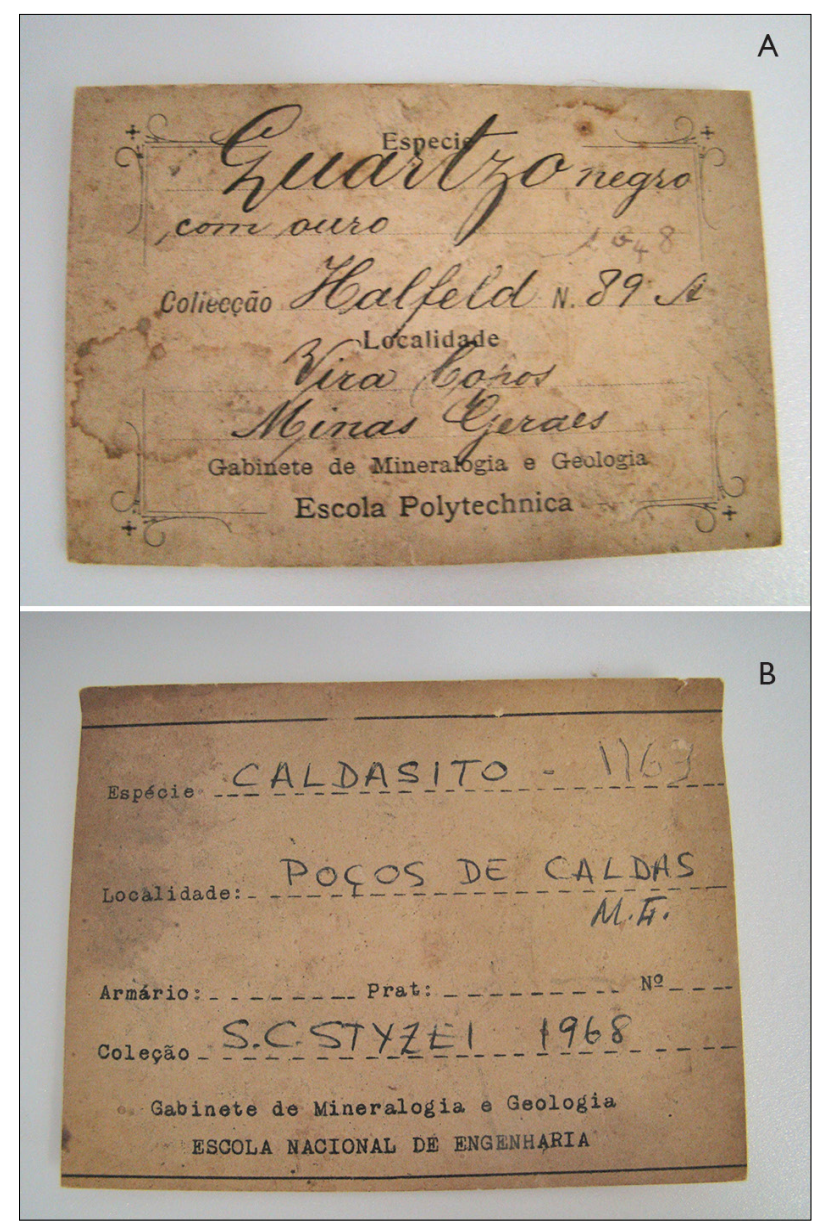

Figura 3. Fichas de identificação da antiga Escola Politécnica (A) e da Escola Nacional de Engenharia (B). Fotos: Cícera Neysi de Almeida.

Assim considerando, é preciso assinalar que os objetos/documentos processados a partir da musealização não se detêm unicamente nos aspectos descritivos da materialidade, do concreto, mas remete-nos sempre aos contextos históricos e socioculturais de sua produção e uso. Estes dois níveis, para se tornarem úteis, devem ser integrados em uma instância significativa cuja construção é inviável sem os pressupostos da documentação. [...] No caso dos museus, não obstante os esforços que vêm sendo realizados, é essencial e urgente $\mathrm{O}$ aprofundamento radical de pesquisas relacionadas à gestão e à transmissão da informação tendo como pano de fundo a documentação (Loureiro, 2008, p. 27-28).

Os desafios do processamento técnico deste acervo mineralógico passam pelas ações corriqueiras de etiquetagem, de assentamentos em livros de registros, de alimentação do banco de dados digital, de organização física, mas essencialmente pelo aprofundamento da pesquisa documental. Passa, enfim, por todo um aparato de medidas que visem, além da organização e da segurança, também a ampliação das possibilidades de estudos dessas coleções.

As fontes primárias aqui citadas foram localizadas no Arquivo Nacional, local que recebeu da UFRJ, em doação, essa massa documental ainda na década de 1970. Este trabalho, também apoiado por bibliografia, fruto da dedicação de renomados pesquisadores, levou a alguns resultados.

O conjunto de minerais e de rochas que compõe o acervo da extinta Escola Nacional de Engenharia incorpora um valor histórico e científico ímpar. A coleção teve o seu núcleo inicial formado em 1824, quando da doação dos exemplares em duplicata do Museu Nacional, com o objetivo de fornecer aos alunos da Academia Real Militar a continuidade dos estudos práticos em Mineralogia. Nos anos posteriores, esse núcleo foi ampliado, por meio de compra e de doações, por exemplo: 1859, doação de Carron du Villards (número desconhecido); 1868, doação do bacharel José de Saldanha Gama Filho (40 exemplares); 1872, compra da coleção de minerais argentíferos de Thomas Rodenas (140 exemplares); 1874, doação de Henri Gorceix; 1881, compra da coleção do conselheiro Miguel Antônio da Silva (número desconhecido); 1883, compra da coleção Halfeld. Esta última destaca-se por ser uma coleção de exemplares brasileiros, principalmente oriundos de Minas Gerais, sendo composta por 4.679 amostras. Entretanto, o número de exemplares registrados é drasticamente reduzido em relação à totalidade original da coleção. Podemos citar a coleção Rodenas, que foi reduzida a 31 exemplares; a coleção Halfeld, a apenas 83 exemplares; e a coleção Gorceix, que não é sequer referenciada.

O processo de recadastramento do acervo mineralógico do Departamento de Geologia, da UFRJ, está em curso, por isso não se pode precisar o quanto foi perdido ao longo do tempo e as sucessivas mudanças

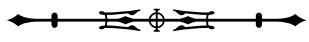


da ENE, mas se pode afirmar que ocorreu um grande encolhimento desse conjunto, que se destaca por sua relevância histórica e científica e que reflete as diferentes épocas e os avanços no ensino em Geociências no país.

\section{AGRADECIMENTOS}

Os autores agradecem à Fundação de Amparo à Pesquisa do Estado do Rio de Janeiro (FAPERJ), pelos recursos financeiros obtidos através dos projetos E-110.125/2008, E-26.111637/2012 e E.30 FAPERJ.2012, que tornaram possível o desenvolvimento deste trabalho. Nosso especial agradecimento ao editor deste periódico, cuja esmerada revisão aperfeiçoou de forma significativa a qualidade deste artigo.

\section{REFERÊNCIAS}

ALMEIDA, C. N., K. L. MANSUR, C. M. BASTOS, P. M. GUIMARÃES, B. R. MIRANDA, J. V. REBOUÇAS \& R. V. ROCHA, 2014. Preservando 55 anos de história e cultura: a Coleção de Minerais do Departamento de Geologia/IGEO/UFRJ. Anais do Congresso Brasileiro de Geologia 47: 1 CD-ROM.

AMARAL, R. F. A., 2011. Modelos didáticos na Museologia e ensino da botânica da Universidade de Coimbra: 1-137. Dissertação (Mestrado em Museologia e Patrimônio Cultural) - Universidade de Coimbra, Coimbra.

ARACRI, E. M. R. P., 2013. Professores no Museu da Geodiversidade: o capital cultural nas percepções e expectativas da relação museu x escola: 1-160. Dissertação (Mestrado em Educação) - Pontifícia Universidade Católica do Rio de Janeiro, Rio de Janeiro.

BARBUY, H., 2008. Documentação museológica e pesquisa em museus. In: MUSEU DE ASTRONOMIA E CIÊNCIAS AFINS (MAST). Documentação em museus: 33-43. MAST (MAST Colloquia, v. 10), Rio de Janeiro.

BARROSO, E. V., J. A. BARROSO, A. E. D. G. HORTA \& I. S. CARVALHO, 2008. 2008: retrospectiva dos 50 anos na Geologia e olhar crítico para o futuro. Anuário IGEO 31(1): 9-23.

BASTOS, C. M., 2016. A Coleção de Minerais e Rochas da Escola Nacional de Engenharia pertencente ao Museu da Geodiversidade/UFRJ: formação e trajetória: 1-112. Dissertação (Mestrado em Museologia e Patrimônio) - Universidade Federal do Estado do Rio de Janeiro/Museu de Astronomia e Ciências Afins, Rio de Janeiro.

BAUDRILLARD, J., 2002. O sistema dos objetos: 1-230. Editora Perspectiva, São Paulo.
BLAKE, A. V. A. S., 1899. Diccionario bibliographico brasileiro: v. 5: 1-495. Typ. Nacional, Rio de Janeiro.

BRASIL, 1813. Decisão n 20 de 22 de junho de 1813 que manda que se hajam por extinto os diferentes empregos do Museu desta Corte. Coleção de Leis do Império do Brasil. Disponível em: < http:// www2.camara.leg.br/atividade-llgislativa/legislacao/publicacoes/ doimperio/colecao1.html>. Acesso em: 16 fevereiro 2015.

BRASIL, 1874. Decreto n. 5.600, de 25 de abril de 1874. Dá estatutos à Escola Polytechnica. Coleção de Leis do Império do Brasil (parte 2): 393 (Publicação original). Disponível em: < http:// www2.camara.leg.br/legin/fed/decret/1824-1899/decreto-560025-abril-1874-550207-publicacaooriginal-65869-pe.html> . Acesso em: 11 novembro 2015

BRASIL, 1937. Lei n. 452, de 5 de julho de 1937. Organiza a Universidade do Brasil. Diário Oficial. Disponível em: < http:// www2.camara.leg.br/legin/fed/lei/1930-1939/lei-452-5-julho-1937398060-retificacao-74976-pl.html > . Acesso em: 8 fevereiro 2015.

CASTRO, A. R. S. F., 2014. Caminhando em direção ao museu inclusivo: diagnóstico de acessibilidade da exposição "Memórias da Terra" (Museu da Geodiversidade - IGEO/UFRJ) com o mapeamento das intervenções necessárias: 1-113. Monografia (Especialização em Acessibilidade Cultural) - Universidade Federal do Rio de Janeiro, Rio de Janeiro.

CASTRO, A. R. S. F., P. D. GRECO, E. M. ROMEIRO, M. C. DIOGO \& I. S. CARVALHO, 2011. A atuação do Museu da Geodiversidade (MGeo-IGeo/UFRJ) na proteção e divulgação do patrimônio geológico. Anais do Simpósio de Geoparques y Geoturismo em Chile 1: 42-45.

CHAGAS, M. S., 1994. Em busca do documento perdido: a problemática de construção teórica na área da documentação. Cadernos de Sociomuseologia 2(2): 41-53.

CURY, M. X., 1999. Museu, filho de Orfeu e musealização. Anais do ICOFOM-LAN 8: 50-55.

DANA, J. D. \& G. J. BRUSH, 1875. A system of mineralogy: descriptive mineralogy, comprising the most recent discoveries: 5 ed.: 1-827. J. Wiley, New York.

DELICADO, A., 2009. A musealização da ciência em Portugal: 1-613. Fundação Calouste Gulbekian, Lisboa.

DOHMANN, M., 2010. O objeto e a experiência material. Arte e Ensaios 20: 71-77.

FIGUEIRÔA, S., 1997. As ciências geológicas no Brasil: uma história social e institucional, 1875-1934: 1-270. HUCITEC, São Paulo.

GROLA, D. A., 2012. O comércio de espécimes na formação das coleções de História Natural do Museu Paulista, 1894-1916. Anais do Seminário Nacional de História da Ciência e da Tecnologia 1: 208-222.

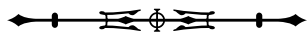


HOWIE, F., 1992. The Care and conservation of geological material: minerals, rocks, meteorites, and lunar finds. Ed. Butterworth-Heinemann, California.

LEINZ, V., 1955. A coleção de minerais do Museu Nacional: comemoração aos 200 anos da Casa de História Natural. Revista Gemologia (2): 1-7.

LOPES, M. M., 2009. O Brasil descobre a pesquisa científica: os museus e as ciências naturais no século XIX: 1-369. Editora Hucitec, São Paulo.

LOUREIRO, J. M. M., 2008. A documentação e suas diversas abordagens: esboço acerca da unidade museológica. In: MUSEU DE ASTRONOMIA E CIÊNCIAS AFINS (MAST). Documentação em Museus: 23-29. MAST (MAST Colloquia, v. 10), Rio de Janeiro.

MOREIRA, H. J. F., 2014. Escola Central: a academia do Largo de São Francisco de Paula que consolidou o ensino de engenharia civil no Brasil: 1-265. Tese (Doutorado em História das Ciências, das Técnicas e da Epistemologia) - Universidade Federal do Rio de Janeiro, Rio de Janeiro.

MORMÊLLO, B. H., 2010. O ensino da matemática na Academia Real Militar do Rio de Janeiro, de 1811 a 1874: 1-191. Dissertação (Mestrado em Matemática) - Universidade Estadual de Campinas, Campinas.

PAPAVERO, N. \& D. M. TEIXEIRA, 2013. Remessa de animais de Santa Catarina (1791) para a "Casa dos Pássaros" no Rio de Janeiro e para o Museu da Ajuda (Portugal). Arquivos de Zoologia 44(4): 183-209. DOI: http://dx.doi.org/10.11606/issn.2176-7793. v44i4p185-209.

POMIAN, K., 1984. Coleção. In: Enciclopédia Einaudi: 51-86. Imprensa Nacional (Memória-História, v. 1), Lisboa.

POSSAS, H. C. G., 2005. Classificar e ordenar: os gabinetes de curiosidades e a história natural. In: B. G. FIGUEIREDO \& D. G. VIDAL (Org.): Museus: dos Gabinetes de Curiosidades à Museologia Moderna: 151-162. Argvmentvm/CNPq (Scientia/UFMG, 5v), Belo Horizonte/Brasília.
RIBEIRO, E. S., 2013. Museus em universidades públicas: entre o campo científico, o ensino e a extensão. Revista Museologia \& Interdisciplinaridade 2(4): 89-102.

RIBEIRO, L. B., 2010. Manias, trecos, objetos e coleção: memória, descarte e velhice nas narrativas quadranísticas de Urbano, o aposentado. Anais do Encontro Regional da ANPUH-Rio 14: 1-9. Disponível em: <http://www.encontro2010.rj.anpuh.org/resources/ anais/8/1276700719 ARQUIVO_anpuh2010textocompleto.pdf>. Acesso em: 25 agosto 2015.

ROUTHIER, P., 1963, Les gisements métallifères: géologie et principes de recherche: 1-1282. Universidade da Califórnia, Masson.

SANTOS, L. B. \& M. L. N. M. LOUREIRO, 2012. Musealização como estratégia de preservação: estudo de caso sobre um previsor de marés. Revista Eletrônica do Programa de Pós-Graduação em Museologia e Patrimônio 5(1): 49-67.

SCHWARCZ, L. M., 2008. O espetáculo das raças: cientistas, instituições e questão racial no Brasil - 1870-1930. Companhia das Letras, São Paulo.

SILVA, M. M. L., E. H. A. GUIMARÃES, W. C. O. JUNIOR, D. M. IZAQUE, C. N. ALMEIDA, C. ARAÚJO \& I. S. CARVALHO, 2008. Museu de Geologia. Anais do Congresso de Extensão da UFRJ 5: 1 CD-ROM.

SUANO, M., 1986. O que é museu. Editora Brasiliense (Coleção Primeiros Passos), São Paulo.

UNIVERSIDADE FEDERAL DO RIO DE JANEIRO (UFRJ), 2010. Regimento interno do Museu da Geodiversidade: 1-8. UFRJ/ IGEO, Rio de Janeiro.

WANDERLEY, M. C. S. \& E. S. RIBEIRO, 2011. Análise museológica do sistema de documentação do Museu de Minerais e Rochas da UFPE. Projeto de pesquisa. UFPE/CTG, Recife. 
